National Science Foundation. We thank Miss Elaine Webster for assistance and Mrs Mary Jane Wade for background material from an unfinished book by herself and Otto Struve.

C. M. WADE

R. M. HJELLMing

National Radio Astronomy Observatory,

Green Bank,

West Virginia

Received January 3, 1972.

1 Wade, C. M., and Hjellming, R. M., Astrophys. J. Lett., 163, L105 (1971).

2 Hjellming, R. M., and Wade, C. M., Astrophys. J. Lett., 168, L115 (1971).

${ }^{3}$ Wade, C. M., Astrophys. J., 162, 381 (1970)

${ }^{4}$ Frieboes-Conde, H., Herczeg, T., and Høg, E., Astron. Astrophys., 4, $78(1970)$

${ }^{5}$ Struve, O., Stellar Evolution, 204 (Princeton Univ. Press, 1950).

6 Struve, O., and Sahade, J., Publ. Astron. Soc. Pacific, 69, 41 (1957).

7 Andrews, P. J., Astrophys. J., 147, 1183 (1967).

${ }^{8}$ Glushneva, I. N., and Esipov, V. F., Sov. Astron. (A. J.), 11, 828 (1968).

9 Wade, C. M., and Hjellming, R. M., Nature, 235, 271 (1972).

10 Devinney, E. J., Nature, 233, 110 (1971)

11 Wilson, R. E., Nature, 234, 406 (1971).

\section{Position and Identification of the Cygnus X-1 Radio Source}

THE initial measurements ${ }^{1,2}$ of the position of the radio source associated with the X-ray source Cygnus $\mathrm{X}-1$ were uncertain by 3 to 5 arc s. The results were consistent with two possible identifications with $\operatorname{stars}^{3}$ : the $8.9 \mathrm{mag}$. BOIb star HDE 226868 ( $\left.=\mathrm{BD}+34^{\circ} 3815\right)$, and a $15 \mathrm{mag}$. red star 9 arc s to the north-west of the $B$ star. Because of the apparent normality of the B star and possible signs of peculiarity in the red $\operatorname{star}^{3}$, it was not clear which should be identified with the radio source. Here, we report the resolution of the ambiguity by an accurate determination of the radio position.

The observations were made at frequencies of 2,695 and $8,085 \mathrm{MHz}$ with the NRAO three-element interferometer at Green Bank from October 28 to October 31, 1971. The baseline lengths were $900,1,800$ and $2,700 \mathrm{~m}$. Cygnus X-1 was observed concurrently with sixty other radio sources in a programme of precise position measurements. The method has been described previously ${ }^{4}$; certain refinements, however, were introduced in the analysis to eliminate the principal sources of systematic error. The procedures and results for the sixty sources will be described in detail later.

The position of the Cygnus $X-1$ radio source, with its standard errors, is found to be:

$$
\begin{aligned}
& \alpha_{1950}=19 \text { h } 56 \mathrm{~m} 28.87 \mathrm{~s} \pm 0.02 \mathrm{~s} \\
& \delta_{1950}=+35^{\circ} 03^{\prime} 55.0^{\prime \prime} \pm 0.3^{\prime \prime} .
\end{aligned}
$$

The AGK2 position of HDE 226868 is

$$
\begin{aligned}
& \alpha_{1950}=19 \text { h } 56 \mathrm{~m} 28.88 \mathrm{~s} \\
& \delta_{1950}=+35^{\circ} 03^{\prime} 54.9^{\prime \prime} .
\end{aligned}
$$

The nearly perfect positional coincidence of the radio source and the star leaves no doubt that HDE 226868 is the correct identification.

During the three-day observing period, the flux density for Cygnus X-1 was $(12 \pm 3) \times 10^{-29} \mathrm{~W} \mathrm{~m}^{2} \mathrm{~Hz}^{-1}$ at $2,695 \mathrm{MHz}$ and $(15 \pm 3) \times 10^{-29} \mathrm{~W} \mathrm{~m} \mathrm{~m}^{-2} \mathrm{~Hz}^{-1}$ at $8,085 \mathrm{MHz}$.

It is now known ${ }^{5,6}$ that HDE 226868 is a spectroscopic binary with a period of 5.6 days. Bolton ${ }^{6}$ has found variable emission lines resembling those of $\mathbf{P}$ Cygni in high-dispersion spectra of this star. This strongly supports the identification of the radio and X-ray sources with the HDE 226868 binary system.
The National Radio Astronomy Observatory is operated by Associated Universities, Inc., under contract with the National Science Foundation.

$$
\begin{aligned}
& \text { C. M. Wade } \\
& \text { R. M. Huellming }
\end{aligned}
$$

National Radio Astronomy Observatory, Green Bank, West Virginia

Received December 31, 1971.

Braes, L. L. E., and Miley, G. K., Nature, 232, 246 (1971).

2 Hjellming, R. M., and Wade, C. M., Astrophys. J. Lett., 168, L21 (1971).

3 Kristian, J., Brucato, R., Visvanathan, N., Lenning, H., and Sandage, A., Astrophys. J. Lett., 168, L91 (1971).

${ }^{4}$ Wade, C. M., Astrophys. J., 162, 381 (1970).

5 Murdin, P., and Webster, B. L., Nature, 235, 37 (1972).

6 Bolton, C. T., Bull. Amer. Astron. Soc., 3, 458 (1971).

\section{Identification of Cygnus X-1 with HDE 226868}

THE ninth magnitude BOlb star HDE 226868 is closely coincident with the position of Cygnus X-1 and its associated variable radio source ${ }^{1}$. Dolan ${ }^{2}$ has pointed out that Cyg X-1 appears to be a two component $\mathrm{X}$-ray source. One component has a synchrotron spectrum, and the other has a thermal (or bremsstrahlung) spectrum. The latter component varies on a time scale of days in a way that suggests it is being eclipsed. Therefore I decided to take photographic spectra of HDE 226868 to look for velocity and spectrum variations that might be correlated with the X-ray fluctuations. I find that the velocity of the star varies with a period consistent with that of the X-ray variation. It may not be possible, however, to interpret the X-ray variations in terms of simple eclipses.

The spectrograms were taken between mid-September and mid-November 1971 with the 74-inch telescope of the David Dunlap Observatory in Richmond Hill, Ontario. All except one were taken at a dispersion of $12 \AA \mathrm{mm}^{-1}$, but because of the star's faintness and unfavourable weather conditions it was necessary to use projected slit widths of 40 to $50 \mu \mathrm{m}$. These observations have been supplemented by results from 5 to $40 \AA \mathrm{mm}^{-1}$ plates taken in one night with the 90 -inch reflector of the Steward Observatory of the University of Arizona. These plates were obtained and measured by Dr Roberta Humphreys, who communicated the results to us before publication. She also provided some additional observations of emission features in the spectrum, and Mr David L. DuPuy

\begin{tabular}{|c|c|c|c|c|c|}
\hline Julian date & $\begin{array}{c}V_{r} \\
\left(\mathrm{~km} \mathrm{~s}^{-1}\right)\end{array}$ & $\begin{array}{l}\text { Standard } \\
\text { deviation } \\
\left(\mathrm{km} \mathrm{s}^{-1}\right)\end{array}$ & $\begin{array}{l}\text { Inter- } \\
\text { stellar } \\
\text { K-line } \\
\left(\mathrm{km} \mathrm{s}^{-1}\right)\end{array}$ & $\begin{array}{c}\mathrm{H} \beta \\
\text { emission } \\
\left(\mathrm{km} \mathrm{s}^{-1}\right)\end{array}$ & $\begin{array}{l}\text { Disper- } \\
\text { sion } \\
\left(\AA \mathrm{mm}^{-1}\right)\end{array}$ \\
\hline $\begin{array}{r}* 2441210.660 \\
1213.665 \\
+1217.588\end{array}$ & $\begin{array}{l}+15 \\
-24 \\
-58\end{array}$ & $\begin{array}{l} \pm 9 \\
\pm 9 \\
\pm 10\end{array}$ & $\begin{array}{l}-19.5 \\
-15.7 \\
-14.3 \\
+74.7\end{array}$ & $\begin{array}{l}+176 \\
+\quad 39\end{array}$ & $\begin{array}{l}43 \\
12 \\
12\end{array}$ \\
\hline $\begin{array}{l}1224.581 \\
1225.696 \\
1237.579 \\
1245.555 \\
1252.549 \\
1259.524 \\
1261.573 \\
+1263.7\end{array}$ & $\begin{array}{l}-41 \\
+33 \\
+57 \\
-48 \\
-62 \\
+56 \\
-15 \\
-65\end{array}$ & $\begin{array}{l} \pm 7 \\
\pm 9 \\
\pm 15 \\
\pm 14 \\
\pm 9 \\
\pm 7 \\
\pm 8 \\
\pm 6\end{array}$ & $\begin{array}{l}-10.7 \\
-15.6 \\
-28.3 \\
-12.6 \\
-15.6 \\
-14.4 \\
-17.2\end{array}$ & +154 & $\begin{array}{l}12 \\
12 \\
12 \\
12 \\
12 \\
12 \\
12 \\
40\end{array}$ \\
\hline
\end{tabular}
of the David Dunlap Observatory obtained UBV photometry of HDE 226868 on three nights.

The results of the radial velocity measures are given in Table 1 and the velocity curve is plotted in Fig. 1 for a period

Table 1 Radial Velocity Measurements

* Unidentified emission feature at $\lambda 4519.10 \AA$.

+ Uncertain identification of $\mathrm{H} \beta$ emission.

$\ddagger$ Mean of five plates taken by Dr Roberta Humphreys. 